\title{
Best proximity results: optimization by approximate solutions
}

\author{
Binayak S Choudhury ${ }^{1}$, Nikhilesh Metiya ${ }^{2}$, Georgeta Maniü ${ }^{3 *}$ and Pulak Konar ${ }^{4}$
}

\author{
"Correspondence: \\ maniugeorgeta@gmail.com \\ ${ }^{3}$ Department of Computer Science, \\ Information Technology, \\ Mathematics and Physics, \\ Petroleum-Gas University of Ploiesti, \\ Bulevardul Bucuresti, Nr. 39, Ploiesti, \\ 100680, Romania \\ Full list of author information is \\ available at the end of the article
}

\begin{abstract}
In this paper we utilize a generalized weakly contractive mapping to establish some best proximity point results which are global optimization results for finding the minimum distances between two sets. Amongst many approaches to this problem, we adopt the approach where the problem is treated as that of finding global optimal approximate solution of the fixed point equation for the generalized weak contraction mapping. We use three control functions to define such mappings. The results are obtained in metric spaces with a partial ordering defined therein. There is a blending of analytic and order theoretic approaches in the proofs. The uniqueness is obtained by imposing some order theoretic conditions additionally. There are several corollaries. An illustration of the main theorem through an example is given which also shows that the corollaries are properly contained in the main theorem.
\end{abstract}

MSC: Primary 47H10;54H10;54H25

Keywords: partially ordered metric space; best proximity point; fixed point equation; approximate solution; optimization

\section{Introduction and mathematical preliminaries}

The program of the paper is to find best proximity pairs between two subsets of a metric space with a partial ordering. There are several works which utilize for that purpose non-self mappings in the following manner. Let $A$ and $B$ be two non-intersecting subsets of a metric space $(X, d)$. A mapping $S: A \longrightarrow B$ realizes the best proximity pair $(x, S x)$ if $d(x, S x)=d(A, B)$. In that case the point $x$ is called a best proximity point of $S$ and the problem of finding such a point is designated as best proximity point problem. This area of research has attracted attention in recent time which has resulted into the publication of a good number of papers as, for instances, those which are noted in [1-16].

The problem has two aspects. Primarily, it is a global minimization problem, where the quantity $d(x, S x)$ is minimized over $x \in A$ subject to the condition that the minimum value is $d(A, B)$. When this global minimum is attained at a point $z$, then we have a best proximity point for which $d(z, S z)=d(A, B)$. Another aspect is that it is an extension of the idea of fixed point to which it reduces in the cases where $A \cap B$ is nonempty. This is the reason that fixed point methodologies are applicable to these category of problems. More elaborately, the problem can be treated as that of finding a global optimal approximate solution of the fixed point equation $x=S x$ even when the exact solution is nonexistent for $A \cap B=\emptyset$, which is the case of interest here. We adopt the latter approach in this paper.

(c) 2016 Choudhury et al. This article is distributed under the terms of the Creative Commons Attribution 4.0 International License (http://creativecommons.org/licenses/by/4.0/), which permits unrestricted use, distribution, and reproduction in any medium, provided you give appropriate credit to the original author(s) and the source, provide a link to the Creative Commons license, and indicate if changes were made. 
We use a generalized weak contraction in our results. Weak contraction was studied in partially ordered metric spaces by Harjani and Sadarangani [17]. In a recent result by Choudhury et al. [18], a generalization of the above result to a coincidence point theorem has been made using three control functions. More specifically, here we utilize a generalized weak contraction mapping defined with the help of three control functions for the purpose of obtaining the desired minimum distance. The above mentioned mapping is assumed to be defined from one set $A$ to the other set $B$. Then under suitable conditions, by applying fixed point methodologies, we obtained a best proximity point of the above mentioned mapping which realizes the minimum distance. Several metric and order theoretic concepts are utilized in our results. The main result has four corollaries and an illustrative example. Separate order theoretic condition are imposed to ensure the uniqueness of the best proximity point in the main result. It is also shown that the corollaries are properly contained in the main theorem.

The following are the requisite mathematical concepts for the discussions in this paper. Throughout the paper $(X, d)$ denotes a metric space, $\preceq$ a partial order on $X$ and $A, B \subseteq X$. We use the following notations:

$$
\begin{aligned}
& d(A, B)=\inf \{d(a, b): a \in A \text { and } b \in B\}, \\
& A_{0}=\{a \in A: d(a, b)=d(A, B) \text { for some } b \in B\}, \\
& B_{0}=\{b \in B: d(a, b)=d(A, B) \text { for some } a \in A\} .
\end{aligned}
$$

It is to be noted that if $(A, B)$ is a nonempty, weakly compact, and convex pair in a Banach space $X$, then $A_{0}$ and $B_{0}$ are nonempty [5, 11]. If a mapping $S: A \cup B \longrightarrow A \cup B$ is cyclic relatively nonexpansive mapping, and $(A, B)$ is a nonempty, weakly compact, and convex pair in a Banach space $X$ then further we have $S\left(A_{0}\right) \subseteq B_{0}$.

Definition 1.1 (P-property [16]) Let $A$ and $B$ be two nonempty subsets of a metric space $(X, d)$ with $A_{0} \neq \emptyset$. Then the pair $(A, B)$ is said to have the $P$-property if, for any $x_{1}, x_{2} \in A_{0}$ and $y_{1}, y_{2} \in B_{0}$,

$$
\left.\begin{array}{l}
d\left(x_{1}, y_{1}\right)=d(A, B), \\
d\left(x_{2}, y_{2}\right)=d(A, B)
\end{array}\right\} \quad \Rightarrow \quad d\left(x_{1}, x_{2}\right)=d\left(y_{1}, y_{2}\right)
$$

In [1], Abkar and Gabeleh show that every nonempty, bounded, closed, and convex pair of subsets of a uniformly convex Banach spaces has the $P$-property. Some non-trivial examples of a nonempty pair of subsets which satisfies the $P$-property are given in [1].

Lemma 1.1 ([10]) Let $(A, B)$ be a pair of nonempty closed subsets of a complete metric space $(X, d)$ such that $A_{0}$ is nonempty and $(A, B)$ has the P-property. Then, $\left(A_{0}, B_{0}\right)$ is a closed pair of subsets of $X$.

Definition 1.2 A mapping $S: A \longrightarrow A$ is said to be increasing if for all $x, y \in A$,

$$
x \preceq y \quad \Longrightarrow \quad S x \preceq S y .
$$


Definition 1.3 ([4]) A mapping $S: A \longrightarrow B$ is called proximally increasing if for all $v_{1}, v_{2}, y_{1}, y_{2} \in A$,

$$
y_{1} \preceq y_{2}, \quad d\left(v_{1}, S y_{1}\right)=d(A, B) \quad \text { and } \quad d\left(v_{2}, S y_{2}\right)=d(A, B) \quad \Longrightarrow \quad v_{1} \preceq v_{2} .
$$

In case of self-mapping the above definition reduces to the definition of increasing mapping.

Definition 1.4 A mapping $S: A \longrightarrow B$ is called proximally increasing on $A_{0}$ if for all $v_{1}, v_{2}, y_{1}, y_{2} \in A_{0}$,

$$
y_{1} \preceq y_{2}, \quad d\left(v_{1}, S y_{1}\right)=d(A, B) \quad \text { and } \quad d\left(v_{2}, S y_{2}\right)=d(A, B) \quad \Longrightarrow \quad v_{1} \preceq v_{2} .
$$

Definition 1.5 The partially ordered metric space $(X, d, \preceq)$ is called regular if it has the following properties:

(i) if $\left\{z_{n}\right\}$ is any nondecreasing sequence in $X$ converging to $z$, then $z_{n} \preceq z$ for any $n \geq 0$;

(ii) if $\left\{z_{n}\right\}$ is any nonincreasing sequence in $X$ converging to $z$, then $z_{n} \succeq z$ for any $n \geq 0$.

\section{Main results}

Let $\Gamma$ and $\Lambda$ denote the following classes of functions:

$\Gamma=\{\eta:[0, \infty) \longrightarrow[0, \infty), \eta$ is continuous and monotonic increasing $\} ;$

$\Lambda=\{\xi:[0, \infty) \longrightarrow[0, \infty), \xi$ is bounded on any bounded interval in $[0, \infty)\}$

Now, we discuss some properties of some special type of functions in $\Lambda$.

Let $\Theta=\left\{\theta \in \Lambda: \underline{\lim } \theta\left(z_{n}\right)>0\right.$, whenever $\left\{z_{n}\right\}$ is any sequence of nonnegative real numbers converging to $l>0\}$.

We note that $\Theta$ is nonempty. For an illustration, we define $\theta_{1}$ on $[0, \infty)$ by $\theta_{1}(x)=e^{2 x}$, $x \in[0, \infty)$. Then $\theta_{1} \in \Theta$. Here we observe that $\theta_{1}(0)=1>0$. On the other hand, if $\theta_{2}(x)=x^{3}$, $x \in[0, \infty)$, then $\theta_{2} \in \Theta$ and $\theta_{2}(0)=0$.

Also, for any $\theta \in \Theta$, it is clear that $\theta(x)>0$ for $x>0$; and $\theta(0)$ need not be equal to 0 .

Let $\Upsilon=\left\{\varphi \in \Lambda: \varlimsup \varphi\left(z_{n}\right)<l\right.$, whenever $\left\{z_{n}\right\}$ is any sequence of nonnegative real numbers converging to $l>0\}$.

It follows from the definition that, for any $\varphi \in \Upsilon, \varphi(y)<y$ for all $y>0$.

Theorem 2.1 Let $(X, d)$ be a complete metric space and $\preceq$ be a partial order on $X$. Let $(A, B)$ be a pair of nonempty subsets of $X$ such that $A_{0}$ is nonempty and closed. Let $S: A \longrightarrow B$ be a mapping with the properties that $S\left(A_{0}\right) \subseteq B_{0}$ and $S$ is proximally increasing on $A_{0}$. Assume that there exist $\eta \in \Gamma$ and $\xi, \theta \in \Lambda$ such that

(i) for $x, y \in[0, \infty), \eta(x) \leq \xi(y) \Longrightarrow x \leq y$,

(ii) $\eta(z)-\varlimsup \overline{\lim } \xi\left(z_{n}\right)+\underline{\lim } \theta\left(z_{n}\right)>0$, whenever $\left\{z_{n}\right\}$ is any sequence of nonnegative real numbers converging to $z>0$,

(iii) for all $x, y, u, v \in A_{0}$

$$
\left.\begin{array}{r}
x \leq y, \\
d(u, S x)=d(A, B), \\
d(v, S y)=d(A, B)
\end{array}\right\} \Rightarrow \eta(d(u, v)) \leq \xi(M(x, y, u, v))-\theta(M(x, y, u, v)),
$$

where $M(x, y, u, v)=\max \left\{d(x, y), \frac{d(x, u)+d(y, v)}{2}, \frac{d(y, u)+d(x, v)}{2}\right\}$. 
Suppose either $S$ is continuous or $X$ is regular. Also, suppose that there exist elements $x_{0}, x_{1} \in A_{0}$ for which $d\left(x_{1}, S x_{0}\right)=d(A, B)$ and $x_{0} \preceq x_{1}$. Then $S$ has a best proximity point in $A_{0}$.

Proof It follows from the definition of $A_{0}$ and $B_{0}$ that for every $x \in A_{0}$ there exists $y \in$ $B_{0}$ such that $d(x, y)=d(A, B)$ and conversely, for every $y^{\prime} \in B_{0}$ there exists $x^{\prime} \in A_{0}$ such that $d\left(x^{\prime}, y^{\prime}\right)=d(A, B)$. Since $S\left(A_{0}\right) \subseteq B_{0}$, for every $x \in A_{0}$ there exists a $y \in A_{0}$ such that $d(y, S x)=d(A, B)$.

By the hypothesis of the theorem there exist $x_{0}, x_{1} \in A_{0}$ for which $x_{0} \preceq x_{1}$ and

$$
d\left(x_{1}, S x_{0}\right)=d(A, B)
$$

Now, $x_{1} \in A_{0}$ and $S\left(A_{0}\right) \subseteq B_{0}$ imply the existence of a point $x_{2} \in A_{0}$ such that

$$
d\left(x_{2}, S x_{1}\right)=d(A, B)
$$

As $S$ is proximally increasing on $A_{0}$, we get $x_{1} \preceq x_{2}$. In this way we obtain a sequence $\left\{x_{n}\right\}$ in $A_{0}$ such that for all $n \geq 0$,

$$
x_{n} \preceq x_{n+1}
$$

and

$$
d\left(x_{n+1}, S x_{n}\right)=d(A, B)
$$

By the hypothesis (iii), $x_{n} \preceq x_{n+1}, d\left(x_{n+1}, S x_{n}\right)=d(A, B)$ and $d\left(x_{n+2}, S x_{n+1}\right)=d(A, B)$ imply that

$$
\eta\left(d\left(x_{n+1}, x_{n+2}\right)\right) \leq \xi\left(M\left(x_{n}, x_{n+1}, x_{n+1}, x_{n+2}\right)\right)-\theta\left(M\left(x_{n}, x_{n+1}, x_{n+1}, x_{n+2}\right)\right),
$$

where

$$
\begin{aligned}
M & \left(x_{n}, x_{n+1}, x_{n+1}, x_{n+2}\right) \\
& =\max \left\{d\left(x_{n}, x_{n+1}\right), \frac{d\left(x_{n}, x_{n+1}\right)+d\left(x_{n+1}, x_{n+2}\right)}{2}, \frac{d\left(x_{n+1}, x_{n+1}\right)+d\left(x_{n}, x_{n+2}\right)}{2}\right\} \\
& =\max \left\{d\left(x_{n}, x_{n+1}\right), \frac{d\left(x_{n}, x_{n+1}\right)+d\left(x_{n+1}, x_{n+2}\right)}{2}, \frac{d\left(x_{n}, x_{n+2}\right)}{2}\right\} .
\end{aligned}
$$

By the triangular inequality, $\frac{d\left(x_{n}, x_{n+2}\right)}{2} \leq \frac{d\left(x_{n}, x_{n+1}\right)+d\left(x_{n+1}, x_{n+2}\right)}{2}$. So, it follows that

$$
M\left(x_{n}, x_{n+1}, x_{n+1}, x_{n+2}\right)=\max \left\{d\left(x_{n}, x_{n+1}\right), \frac{d\left(x_{n}, x_{n+1}\right)+d\left(x_{n+1}, x_{n+2}\right)}{2}\right\} .
$$

Let $U_{n}=d\left(x_{n}, x_{n+1}\right)$, for all $n \geq 0$.

Case 1: $M\left(x_{n}, x_{n+1}, x_{n+1}, x_{n+2}\right)=d\left(x_{n}, x_{n+1}\right)$. Then by (2.5),

$$
\eta\left(d\left(x_{n+1}, x_{n+2}\right)\right) \leq \xi\left(d\left(x_{n}, x_{n+1}\right)\right)-\theta\left(d\left(x_{n}, x_{n+1}\right)\right),
$$


that is,

$$
\eta\left(U_{n+1}\right) \leq \xi\left(U_{n}\right)-\theta\left(U_{n}\right)
$$

which implies that $\eta\left(U_{n+1}\right) \leq \xi\left(U_{n}\right)$. Then it follows by the hypothesis (i) of the theorem that $U_{n+1} \leq U_{n}$, for all $n \geq 0$.

Case 2: $M\left(x_{n}, x_{n+1}, x_{n+1}, x_{n+2}\right)=\frac{d\left(x_{n}, x_{n+1}\right)+d\left(x_{n+1}, x_{n+2}\right)}{2}=\frac{U_{n}+U_{n+1}}{2}=V_{n}$ (say). Then it follows from (2.5) that

$$
\eta\left(U_{n+1}\right) \leq \xi\left(V_{n}\right)-\theta\left(V_{n}\right)
$$

which implies that $\eta\left(U_{n+1}\right) \leq \xi\left(V_{n}\right)=\xi\left(\frac{U_{n+1}+U_{n}}{2}\right)$. Again by the hypothesis (i) the theorem it follows that $U_{n+1} \leq \frac{U_{n}+U_{n+1}}{2}$, that is, $U_{n+1} \leq U_{n}$, for all $n \geq 0$.

From Case 1 and Case 2, we conclude that $\left\{U_{n}\right\}$ is a monotone decreasing sequence of nonnegative real numbers. As $\left\{U_{n}\right\}$ is bounded below by zero, there exists an $t \geq 0$ such that

$$
\lim _{n \rightarrow \infty} U_{n}=d\left(x_{n}, x_{n+1}\right)
$$

Then it follows that

$$
\lim _{n \rightarrow \infty} V_{n}=\frac{d\left(x_{n}, x_{n+1}\right)+d\left(x_{n+1}, x_{n+2}\right)}{2} .
$$

Taking the limit supremum in both sides of the inequality (2.6), using (2.8), the continuity of $\eta$, and the property of $\xi$ and $\theta$, we obtain

$$
\eta(t) \leq \varlimsup \overline{\lim } \xi\left(U_{n}\right)+\varlimsup\left(-\theta\left(U_{n}\right)\right) .
$$

Since $\varlimsup\left(-\theta\left(U_{n}\right)\right)=-\underline{\lim } \theta\left(U_{n}\right)$, it follows that

$$
\eta(t) \leq \varlimsup \overline{\lim } \xi\left(U_{n}\right)-\underline{\lim } \theta\left(U_{n}\right),
$$

that is,

$$
\eta(t)-\varlimsup \overline{\lim } \xi\left(U_{n}\right)+\underline{\lim } \theta\left(U_{n}\right) \leq 0,
$$

which, by the hypothesis (ii) and (2.8), is a contradiction unless $t=0$.

Arguing similarly as above, from (2.7) and (2.8), we have

$$
\eta(t)-\varlimsup \overline{\lim } \xi\left(V_{n}\right)+\underline{\lim } \theta\left(V_{n}\right) \leq 0,
$$

which, by the hypothesis (ii) and (2.9), is a contradiction unless $t=0$. Hence

$$
U_{n}=d\left(x_{n}, x_{n+1}\right) \longrightarrow 0 \quad \text { as } n \longrightarrow \infty
$$

Next we show that $\left\{x_{n}\right\}$ is a Cauchy sequence. 
Suppose that $\left\{x_{n}\right\}$ is not a Cauchy sequence. Then there exist $\delta>0$ and two sequences $\{m(k)\}$ and $\{n(k)\}$ of positive integers such that for all positive integers $k, n(k)>m(k)>k$ and $d\left(x_{m(k)}, x_{n(k)}\right) \geq \delta$. Assuming that $n(k)$ is the smallest such positive integer, we get

$$
n(k)>m(k)>k, \quad d\left(x_{m(k)}, x_{n(k)}\right) \geq \delta \quad \text { and } \quad d\left(x_{m(k)}, x_{n(k)-1}\right)<\delta .
$$

Now,

$$
\delta \leq d\left(x_{m(k)}, x_{n(k)}\right) \leq d\left(x_{m(k)}, x_{n(k)-1}\right)+d\left(x_{n(k)-1}, x_{n(k)}\right)<\delta+d\left(x_{n(k)-1}, x_{n(k)}\right) .
$$

From the above inequality and (2.10), it follows that

$$
\lim _{k \rightarrow \infty} d\left(x_{m(k)}, x_{n(k)}\right)=\delta
$$

Again,

$$
d\left(x_{m(k)}, x_{n(k)}\right) \leq d\left(x_{m(k)}, x_{m(k)+1}\right)+d\left(x_{m(k)+1}, x_{n(k)+1}\right)+d\left(x_{n(k)+1}, x_{n(k)}\right)
$$

and

$$
d\left(x_{m(k)+1}, x_{n(k)+1}\right) \leq d\left(x_{m(k)+1}, x_{m(k)}\right)+d\left(x_{m(k)}, x_{n(k)}\right)+d\left(x_{n(k)}, x_{n(k)+1}\right) .
$$

The above two inequalities imply that

$$
\begin{aligned}
& d\left(x_{m(k)}, x_{n(k)}\right)-d\left(x_{m(k)}, x_{m(k)+1}\right)-d\left(x_{n(k)+1}, x_{n(k)}\right) \\
& \quad \leq d\left(x_{m(k)+1}, x_{n(k)+1}\right) \leq d\left(x_{m(k)+1}, x_{m(k)}\right)+d\left(x_{m(k)}, x_{n(k)}\right)+d\left(x_{n(k)}, x_{n(k)+1}\right) .
\end{aligned}
$$

From the above inequality, (2.10) and (2.11), we have

$$
\lim _{k \rightarrow \infty} d\left(x_{m(k)+1}, x_{n(k)+1}\right)=\delta
$$

Again,

$$
d\left(x_{m(k)}, x_{n(k)}\right) \leq d\left(x_{m(k)}, x_{n(k)+1}\right)+d\left(x_{n(k)+1}, x_{n(k)}\right)
$$

and

$$
d\left(x_{m(k)}, x_{n(k)+1}\right) \leq d\left(x_{m(k)}, x_{n(k)}\right)+d\left(x_{n(k)}, x_{n(k)+1}\right) .
$$

The above two inequalities imply that

$$
d\left(x_{m(k)}, x_{n(k)}\right)-d\left(x_{n(k)+1}, x_{n(k)}\right) \leq d\left(x_{m(k)}, x_{n(k)+1}\right) \leq d\left(x_{m(k)}, x_{n(k)}\right)+d\left(x_{n(k)}, x_{n(k)+1}\right) .
$$

From the above inequality, (2.10) and (2.11), we have

$$
\lim _{k \rightarrow \infty} d\left(x_{m(k)}, x_{n(k)+1}\right)=\delta
$$


Similarly, we can prove that

$$
\lim _{k \rightarrow \infty} d\left(x_{n(k)}, x_{m(k)+1}\right)=\delta .
$$

By the construction of the sequence $\left\{x_{n}\right\}$, we have

$$
x_{m(k)} \preceq x_{n(k)}, \quad d\left(x_{m(k)+1}, S x_{m(k)}\right)=d(A, B) \quad \text { and } \quad d\left(x_{n(k)+1}, S x_{n(k)}\right)=d(A, B),
$$

which, by the hypothesis (iii), imply that

$$
\begin{aligned}
& \eta\left(d\left(x_{m(k)+1}, x_{n(k)+1}\right)\right) \\
& \quad \leq \xi\left(M\left(x_{m(k)}, x_{n(k)}, x_{m(k)+1}, x_{n(k)+1}\right)\right)-\theta\left(M\left(x_{m(k)}, x_{n(k)}, x_{m(k)+1}, x_{n(k)+1}\right)\right),
\end{aligned}
$$

where

$$
\begin{aligned}
M\left(x_{m(k)}, x_{n(k)}, x_{m(k)+1}, x_{n(k)+1}\right) & \\
= & \max \left\{d\left(x_{m(k)}, x_{n(k)}\right), \frac{d\left(x_{m(k)}, x_{m(k)+1}\right)+d\left(x_{n(k)}, x_{n(k)+1}\right)}{2},\right. \\
& \left.\frac{d\left(x_{n(k)}, x_{m(k)+1}\right)+d\left(x_{m(k)}, x_{n(k)+1}\right)}{2}\right\} .
\end{aligned}
$$

From (2.10), (2.11), (2.13), and (2.14), it follows that

$$
\lim _{k \rightarrow \infty} M\left(x_{m(k)}, x_{n(k)}, x_{m(k)+1}, x_{n(k)+1}\right)=\delta .
$$

Taking the limit supremum in both sides of the inequality (2.15), using (2.12), (2.16), the continuity of $\eta$, and the property of $\xi$ and $\theta$, we obtain

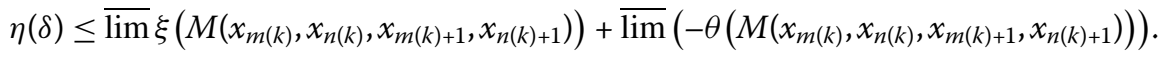

As $\varlimsup\left(-\theta\left(M\left(x_{m(k)}, x_{n(k)}, x_{m(k)+1}, x_{n(k)+1}\right)\right)\right)=-\underline{\lim } \theta\left(M\left(x_{m(k)}, x_{n(k)}, x_{m(k)+1}, x_{n(k)+1}\right)\right)$, it follows that

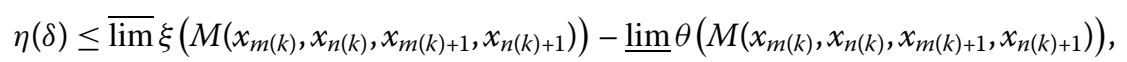

that is,

$$
\eta(\delta)-\varlimsup \xi \xi\left(M\left(x_{m(k)}, x_{n(k)}, x_{m(k)+1}, x_{n(k)+1}\right)\right)+\underline{\lim } \theta\left(M\left(x_{m(k)}, x_{n(k)}, x_{m(k)+1}, x_{n(k)+1}\right)\right) \leq 0,
$$

which, by the hypothesis (ii) and (2.16), is a contradiction. Therefore, $\left\{x_{n}\right\}$ is a Cauchy sequence in $A_{0}$. Since $A_{0}$ is a closed subset of complete metric space $(X, d)$, there exists $a \in A_{0}$ such that

$$
\lim _{n \rightarrow \infty} x_{n}=a ; \quad \text { that is, } \lim _{n \rightarrow \infty} d\left(x_{n}, a\right)=0 .
$$

- Suppose that $S$ is continuous.

Taking $n \longrightarrow \infty$ in (2.4) and using the continuity of $S$, we have $d(a, S a)=d(A, B)$; that is, $a$ is a best proximity point of $S$. 
- Next we suppose that $X$ is regular.

By (2.3) and (2.17), we have

$$
x_{n} \preceq a \text { for all } n \geq 0 .
$$

Now $a \in A_{0}$ and $S\left(A_{0}\right) \subseteq B_{0}$ imply the existence of a point $p \in A_{0}$ for which

$$
d(p, S a)=d(A, B)
$$

By (2.4), (2.18) and (2.19), we have

$$
x_{n} \preceq a, \quad d\left(x_{n+1}, S x_{n}\right)=d(A, B) \quad \text { and } \quad d(p, S a)=d(A, B),
$$

which, by the hypothesis (iii) of the theorem, imply that

$$
\eta\left(d\left(x_{n+1}, p\right)\right) \leq \xi\left(M\left(x_{n}, a, x_{n+1}, p\right)\right)-\theta\left(M\left(x_{n}, a, x_{n+1}, p\right)\right),
$$

where

$$
M\left(x_{n}, a, x_{n+1}, p\right)=\max \left\{d\left(x_{n}, a\right), \frac{d\left(x_{n}, x_{n+1}\right)+d(a, p)}{2}, \frac{d\left(a, x_{n+1}\right)+d\left(x_{n}, p\right)}{2}\right\} .
$$

From (2.17), it follows that

$$
\lim _{n \rightarrow \infty} M\left(x_{n}, a, x_{n+1}, p\right)=\frac{d(a, p)}{2} .
$$

Taking the limit supremum in both sides of the inequality (2.20), using (2.17), (2.21), the properties of $\eta$, and the property of $\xi$ and $\theta$, we obtain

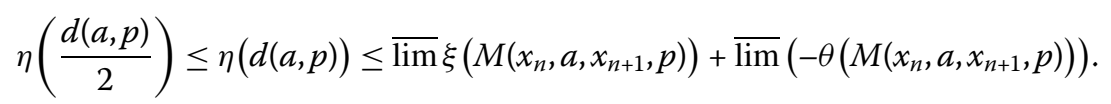

Arguing similarly as discussed above, we have

$$
\eta\left(\frac{d(a, p)}{2}\right)-\varlimsup \xi\left(M\left(x_{n}, a, x_{n+1}, p\right)\right)+\underline{\lim } \theta\left(M\left(x_{n}, a, x_{n+1}, p\right)\right) \leq 0,
$$

which, by the hypothesis (ii) and (2.21), is a contradiction unless $d(a, p)=0$; that is, $p=a$. Then by (2.19) we have $d(a, S a)=d(A, B)$; that is, $a$ is a best proximity point of $S$.

Theorem 2.2 In addition to the hypotheses of Theorem 2.1, suppose that for every $x, y \in A_{0}$ there exists $u \in A_{0}$ such that $u$ is comparable to $x$ and $y$. Then $S$ has a unique best proximity point.

Proof By Theorem 2.1, the set of best proximity points of $S$ is nonempty. Suppose $x, y \in A_{0}$ are two best proximity points of $S$; that is,

$$
d(x, S x)=d(A, B) \quad \text { and } \quad d(y, S y)=d(A, B) .
$$

By the assumption, there exists $u \in A_{0}$, which is comparable with $x$ and $y$. 
Put $u_{0}=u$. Suppose that

$u_{0} \preceq x \quad$ (in the other case the proof is similar).

$S\left(A_{0}\right) \subseteq B_{0}$ and $u_{0}=u \in A_{0}$ imply the existence of a point $u_{1} \in A_{0}$ for which

$$
d\left(u_{1}, S u_{0}\right)=d(A, B)
$$

Since $S$ is proximally increasing on $A_{0}$, from (2.22), (2.23), and (2.24) we have

$$
u_{1} \preceq x .
$$

Following this process, we obtain a sequence $\left\{u_{n}\right\}$ in $A_{0}$ such that for all $n \geq 0$,

$$
d\left(u_{n+1}, S u_{n}\right)=d(A, B) \text { and } \quad u_{n} \preceq x
$$

By (2.22) and (2.26), we have

$$
u_{n} \preceq x, \quad d\left(u_{n+1}, S u_{n}\right)=d(A, B) \quad \text { and } \quad d(x, S x)=d(A, B),
$$

which, by the hypothesis (iii) of Theorem 2.1, imply that

$$
\eta\left(d\left(u_{n+1}, x\right)\right) \leq \xi\left(M\left(u_{n}, x, u_{n+1}, x\right)\right)-\theta\left(M\left(u_{n}, x, u_{n+1}, x\right)\right),
$$

where

$$
\begin{aligned}
M\left(u_{n}, x, u_{n+1}, x\right) & =\max \left\{d\left(u_{n}, x\right), \frac{d\left(u_{n}, u_{n+1}\right)+d(x, x)}{2}, \frac{d\left(x, u_{n+1}\right)+d\left(u_{n}, x\right)}{2}\right\} \\
& =\max \left\{d\left(u_{n}, x\right), \frac{d\left(u_{n}, u_{n+1}\right)}{2}, \frac{d\left(x, u_{n+1}\right)+d\left(u_{n}, x\right)}{2}\right\} .
\end{aligned}
$$

By the triangular inequality $\frac{d\left(u_{n}, u_{n+1}\right)}{2} \leq \frac{d\left(x, u_{n+1}\right)+d\left(u_{n}, x\right)}{2}$. Then it follows that

$$
M\left(u_{n}, x, u_{n+1}, x\right)=\max \left\{d\left(u_{n}, x\right), \frac{d\left(x, u_{n+1}\right)+d\left(u_{n}, x\right)}{2}\right\} .
$$

Let $Q_{n}=d\left(u_{n}, x\right)$, for all $n \geq 0$.

Arguing similarly as in the proof of Theorem 2.1 (Case 1 and Case 2), we can prove that $\left\{Q_{n}\right\}$ is a monotone decreasing sequence of nonnegative real numbers and

$$
\lim _{n \rightarrow \infty} Q_{n}=\lim _{n \rightarrow \infty} d\left(u_{n}, x\right)=0
$$

Similarly, we show that

$$
\lim _{n \rightarrow \infty} d\left(u_{n}, y\right)=0
$$

By the triangle inequality, and using (2.28) and (2.29), we have

$$
0 \leq d(x, y) \leq\left[d\left(x, u_{n}\right)+d\left(u_{n}, y\right)\right] \longrightarrow 0 \quad \text { as } n \longrightarrow \infty
$$


which implies that $d(x, y)=0$; that is, $x=y$; that is, the best proximity point of $S$ is unique.

With the help of $P$-property we have the following theorem which is obtained by an application of Theorem 2.1.

Theorem 2.3 Let $(X, d)$ be a complete metric space and $\preceq$ be a partial order on $X$. Let $(A, B)$ be a pair of nonempty and closed subsets of $X$ such that $A_{0}$ is nonempty and $(A, B)$ satisfies the P-property. Let $S: A \longrightarrow B$ be a mapping with the properties that $S\left(A_{0}\right) \subseteq B_{0}$ and $S$ is proximally increasing on $A_{0}$. Assume that there exist $\eta \in \Gamma$ and $\xi, \theta \in \Lambda$ such that

(i) for $x, y \in[0, \infty), \eta(x) \leq \xi(y) \Longrightarrow x \leq y$,

(ii) $\eta(z)-\varlimsup \xi \xi\left(z_{n}\right)+\underline{\lim } \theta\left(z_{n}\right)>0$, whenever $\left\{z_{n}\right\}$ is any sequence of nonnegative real numbers converging to $z>0$,

(iii) for all $x, y, u, v \in A_{0}$

$$
\left.\begin{array}{r}
x \preceq y, \\
d(u, S x)=d(A, B), \\
d(v, S y)=d(A, B)
\end{array}\right\} \Rightarrow \eta(d(S x, S y)) \leq \xi(M(x, y, u, v))-\theta(M(x, y, u, v))
$$

where $M(x, y, u, v)=\max \left\{d(x, y), \frac{d(x, u)+d(y, v)}{2}, \frac{d(y, u)+d(x, v)}{2}\right\}$.

Suppose either $S$ is continuous or $X$ is regular. Also, suppose that there exist elements $x_{0}, x_{1} \in A_{0}$ for which $d\left(x_{1}, S x_{0}\right)=d(A, B)$ and $x_{0} \preceq x_{1}$. Then $S$ has a best proximity point in $A_{0}$.

Proof By Lemma 1.1, $A_{0}$ is nonempty and closed. Since $(A, B)$ satisfies the $P$-property, $d(u, S x)=d(A, B)$ and $d(v, S y)=d(A, B)$ imply that $d(u, v)=d(S x, S y)$. Then condition (iii) of the theorem reduces to the condition (iii) of Theorem 2.1. Therefore, all the conditions of the Theorem 2.1 are satisfied and hence we have the required proof.

\section{Corollaries and example}

Corollary 3.1 Let $(X, d)$ be a complete metric space and $\preceq$ be a partial order on $X$. Let $(A, B)$ be a pair of nonempty subsets of $X$ such that $A_{0}$ is nonempty and closed. Let $S: A \longrightarrow$ $B$ be a mapping with the properties that $S\left(A_{0}\right) \subseteq B_{0}$ and $S$ is proximally increasing on $A_{0}$. Let there exists $\xi \in \Lambda$ such that $\varlimsup \xi\left(z_{n}\right)<z$, whenever $\left\{z_{n}\right\}$ is any sequence of nonnegative real numbers converging to $z>0$ and for all $x, y, u, v \in A_{0}$

$$
\left.\begin{array}{r}
x \preceq y, \\
d(u, S x)=d(A, B), \\
d(v, S y)=d(A, B)
\end{array}\right\} \Rightarrow d(u, v) \leq \xi(M(x, y, u, v))
$$

where $M(x, y, u, v)$ is the same as in Theorem 2.1. Suppose either $S$ is continuous or $X$ is regular. Also, suppose that there exist elements $x_{0}, x_{1} \in A_{0}$ such that $d\left(x_{1}, S x_{0}\right)=d(A, B)$ and $x_{0} \preceq x_{1}$. Then $S$ has a best proximity point in $A_{0}$.

Proof Let $\eta$ be the identity mapping and $\theta(t)=0$ for all $t \in[0, \infty)$ in Theorem 2.1. Then we have the required proof from that of Theorem 2.1. 
Corollary 3.2 Let $(X, d)$ be a complete metric space and $\preceq$ be a partial order on $X$. Let $(A, B)$ be a pair of nonempty subsets of $X$ such that $A_{0}$ is nonempty and closed. Let $S: A \longrightarrow$ $B$ be a mapping with the properties that $S\left(A_{0}\right) \subseteq B_{0}$ and $S$ is proximally increasing on $A_{0}$. Assume that there exist $\eta \in \Gamma$ and $\theta \in \Lambda$ such that for any sequence of nonnegative real numbers $\left\{z_{n}\right\}$ with $z_{n} \longrightarrow z>0, \underline{\lim } \theta\left(z_{n}\right)>0$ and for all $x, y, u, v \in A_{0}$

$$
\left.\begin{array}{r}
x \leq y, \\
d(u, S x)=d(A, B), \\
d(v, S y)=d(A, B)
\end{array}\right\} \Rightarrow \eta(d(u, v)) \leq \eta(M(x, y, u, v))-\theta(M(x, y, u, v))
$$

where $M(x, y, u, v)$ is the same as in Theorem 2.1. Suppose either $S$ is continuous or $X$ is regular. Also, suppose that there exist elements $x_{0}, x_{1} \in A_{0}$ for which $d\left(x_{1}, S x_{0}\right)=d(A, B)$ and $x_{0} \preceq x_{1}$. Then $S$ has a best proximity point in $A_{0}$.

Proof The required proof is obtained by considering $\xi$ to be identical with the function $\eta$ in Theorem 2.1.

Corollary 3.3 Let $(X, d)$ be a complete metric space and $\preceq$ be a partial order on $X$. Let $(A, B)$ be a pair of nonempty subsets of $X$ such that $A_{0}$ is nonempty and closed. Let $S: A \longrightarrow$ $B$ be a mapping with the properties that $S\left(A_{0}\right) \subseteq B_{0}$ and $S$ is proximally increasing on $A_{0}$. Let there exists $\theta \in \Lambda$ such that $\underline{\lim } \theta\left(z_{n}\right)>0$, whenever $\left\{z_{n}\right\}$ is any sequence of nonnegative real numbers converging to $z>0$ and for all $x, y, u, v \in A_{0}$

$$
\left.\begin{array}{r}
x \leq y, \\
d(u, S x)=d(A, B), \\
d(v, S y)=d(A, B)
\end{array}\right\} \Rightarrow d(u, v) \leq M(x, y, u, v)-\theta(M(x, y, u, v)),
$$

where $M(x, y, u, v)$ is the same as in Theorem 2.1. Suppose either $S$ is continuous or $X$ is regular. Also, suppose that there exist elements $x_{0}, x_{1} \in A_{0}$ for which $d\left(x_{1}, S x_{0}\right)=d(A, B)$ and $x_{0} \preceq x_{1}$. Then $S$ has a best proximity point in $A_{0}$.

Proof Let $\eta$ and $\xi$ be the identity mappings in Theorem 2.1. Then we have the required proof from that of Theorem 2.1.

Corollary 3.4 Let $(X, d)$ be a complete metric space and $\preceq$ be a partial order on $X$. Let $(A, B)$ be a pair of nonempty subsets of $X$ such that $A_{0}$ is nonempty and closed. Let $S: A \longrightarrow$ $B$ be a mapping with the properties that $S\left(A_{0}\right) \subseteq B_{0}$ and $S$ is proximally increasing on $A_{0}$. Assume that there exists $k \in[0,1)$ such that for all $x, y, u, v \in A_{0}$

$$
\left.\begin{array}{r}
x \leq y, \\
d(u, S x)=d(A, B), \\
d(v, S y)=d(A, B)
\end{array}\right\} \Rightarrow d(u, v) \leq k M(x, y, u, v),
$$

where $M(x, y, u, v)$ is the same as in Theorem 2.1. Suppose either $S$ is continuous or $X$ is regular. Also, suppose that there exist elements $x_{0}, x_{1} \in A_{0}$ for which $d\left(x_{1}, S x_{0}\right)=d(A, B)$ and $x_{0} \preceq x_{1}$. Then $S$ has a best proximity point in $A_{0}$. 
Proof We consider that $\eta$ and $\xi$ are the identity mappings and $\theta(t)=(1-k) t$, where $0 \leq$ $k<1$, in Theorem 2.1. Then we have the required proof from that of Theorem 2.1.

Example 3.1 Let $X=\mathbb{R}^{2}$ ( $\mathbb{R}$ denotes the set of all real numbers) and $d$ be a metric on $X$ defined as $d(x, y)=\left|x_{1}-x_{2}\right|+\left|y_{1}-y_{2}\right|$, for $x=\left(x_{1}, y_{1}\right), y=\left(x_{2}, y_{2}\right) \in X$. Define a partial order $\preceq$ on $X$ such that $(x, y) \preceq(u, v)$ if and only if $x \leq u$ and $y \leq v$, for all $(x, y),(u, v) \in X$. Let

$$
\begin{aligned}
& A=\{(x, 1): 0 \leq x \leq 1\} \cup\{(0, x): 1 \leq x<2\}, \\
& B=\{(x,-1): 0 \leq x \leq 1\} \cup\{(0, x):-2<x \leq-1\}, \\
& A_{0}=\{(x, 1): 0 \leq x \leq 1\} \subseteq A \text { and } B_{0}=\{(x,-1): 0 \leq x \leq 1\} \subseteq B .
\end{aligned}
$$

Let $S: A \rightarrow B$ be defined as

$$
S(t)= \begin{cases}\left(\frac{x}{2},-1\right), & \text { if } t=(x, 1) \in A_{0}, \\ (0,-x), & \text { if } t=(0, x) \in\{(0, x): 1 \leq x<2\},\end{cases}
$$

and $\eta, \xi, \theta:[0, \infty) \longrightarrow[0, \infty)$ be defined as follows:

$$
\eta(x)=x^{2}, \quad \xi(x)=\frac{x^{2}}{2}, \quad \theta(x)= \begin{cases}0, & \text { if } 0 \leq x \leq 1, \\ \frac{x^{2}}{4}, & \text { otherwise. }\end{cases}
$$

The function $S$ now satisfies all the postulates of Theorems 2.1 and 2.2. Then, by joint applications of Theorems 2.1 and 2.2 we conclude that $S$ must have a best proximity point which is unique. The point can be seen here to be $(0,1) \in A_{0}$.

Note In this example $A$ and $B$ are not closed sets. This is an illustration of the fact that the closedness of $A$ and $B$ are not required in our theorem.

Remark 3.1 Corollaries 3.1, 3.2, 3.3, and 3.4 are not applicable to this example and hence Theorem 2.1 is an actual extension of its Corollaries 3.1, 3.2, 3.3, and 3.4.

\section{Conclusions}

The present paper is an application of weak inequalities satisfied by non-self mappings. Weak contractions are intermediate to the contractions and non-expansions which have been generalized in various ways and have been utilized in different types of problem. We make such an application for finding a best proximity pair. The speciality of this paper is that it has been obtained in the most general settings of a metric space without any special assumptions on this space.

Competing interests

The authors declare that they have no competing interests.

Authors' contributions

The authors contributed equally to this work.

Author details

${ }^{1}$ Department of Mathematics, Indian Institute of Engineering Science and Technology, Shibpur, Howrah, West Bengal 711103, India. ${ }^{2}$ Department of Mathematics, Sovarani Memorial College, Jagatballavpur, Howrah, West Bengal 711408, India. ${ }^{3}$ Department of Computer Science, Information Technology, Mathematics and Physics, Petroleum-Gas University of Ploiesti, Bulevardul Bucuresti, Nr. 39, Ploiesti, 100680, Romania. ${ }^{4}$ Department of Mathematics, NITMAS, South 24 Pargana, Alipore, West Bengal 743368, India. 


\section{Acknowledgements}

The authors gratefully acknowledge the suggestions made by the learned referee.

Received: 25 November 2015 Accepted: 30 June 2016 Published online: 15 July 2016

\section{References}

1. Abkar, A, Gabeleh, M: Global optimal solutions of noncyclic mappings in metric spaces. J. Optim. Theory Appl. 153, 298-305 (2012)

2. Abkar, A, Gabeleh, M: A best proximity point theorem for Suzuki type contraction non-self-mappings. Fixed Point Theory 14, 281-288 (2013)

3. Abkar, A, Gabeleh, M: A note on some best proximity point theorems proved under P-property. Abstr. Appl. Anal. 2013, Article ID 189567 (2013)

4. Basha, SS: Discrete optimization in partially ordered sets. J. Glob. Optim. 54, 511-517 (2012)

5. Basha, SS, Veeramani, P: Best proximity pair theorems for multi functions with open fibres. J. Approx. Theory 103, 119-129 (2000)

6. Choudhury, BS, Maity, P, Konar, P: A global optimality result using nonself mappings. Opsearch 51, $312-320$ (2014)

7. Choudhury, BS, Maity, P, Metiya, N: Best proximity point theorems with cyclic mappings in setvalued analysis. Indian J. Math. 57, 79-102 (2015)

8. Dimri, RC, Semwal, P: Best proximity results for multivalued mappings. Int. J. Math. Anal. 7, 1355-1362 (2013)

9. Eldred, AA, Veeramani, P: Existence and convergence of best proximity points. J. Math. Anal. Appl. 323, 1001-1006 (2006)

10. Gabeleh, M: Proximal weakly contractive and proximal nonexpansive non-self-mappings in metric and Banach spaces. J. Optim. Theory Appl. 158, 615-625 (2013)

11. Gabeleh, M: Best proximity point theorems via proximal non-self mappings. J. Optim. Theory Appl. 164, 565-576 (2015)

12. Gupta, A, Rajput, SS, Kaurav, PS: Coupled best proximity point theorem in metric spaces. Int. J. Anal. Appl. 4, 201-215 (2014)

13. Hussain, N, Kutbi, MA, Salimi, P: Best proximity point results for modified $\alpha$ - $\psi$-proximal rational contractions. Abstr. Appl. Anal. 2013, Article ID 927457 (2013)

14. Karapinar, E, Erhan, IM: Best proximity point on different type contractions. Appl. Math. Inf. Sci. 5(3), 558-569 (2011)

15. Kumam, P, Salimi, P, Vetro, C: Best proximity point results for modified $\alpha$-proximal C-contraction mappings. Fixed Point Theory Appl. 2014, Article ID 99 (2014)

16. Sankar Raj, V: A best proximity point theorem for weakly contractive non-self-mappings. Nonlinear Anal., Theory Methods Appl. 74, 4804-4808 (2011)

17. Harjani, J, Sadarangani, K: Fixed point theorems for weakly contractive mappings in partially ordered sets. Nonlinear Anal. 71, 3403-3410 (2009)

18. Choudhury, BS, Metiya, N, Postolache, M: A generalized weak contraction principle with applications to coupled coincidence point problems. Fixed Point Theory Appl. 2013, Article ID 152 (2013)

\section{Submit your manuscript to a SpringerOpen ${ }^{\circ}$ journal and benefit from:}

- Convenient online submission

Rigorous peer review

- Immediate publication on acceptance

- Open access: articles freely available online

- High visibility within the field

- Retaining the copyright to your article 